\title{
Postoperative Gamma Knife surgery for benign meningiomas of the cranial base
}

\author{
Laurence Davidson, M.D., ${ }^{1}$ Dawn Fishback, P.A., ${ }^{1}$ Jonathan J. Russin, M.D., ${ }^{1}$ \\ Martin H. Weiss, M.D., ${ }^{1}$ Cheng Yu, Ph.D., ${ }^{1}$ Paul G. Pagnini, M.D., ${ }^{2}$ \\ Vladimir Zelman, M.D., Ph.D., ${ }^{3}$ Michael L. J. Apuzzo, M.D., ${ }^{1}$ \\ and Steven L. GiannotTa, M.D. ${ }^{1}$ \\ Departments of ${ }^{1}$ Neurosurgery, ${ }^{2}$ Radiation Oncology, and ${ }^{3}$ Anesthesiology, Keck School of Medicine, \\ University of Southern California, Los Angeles, California
}

\begin{abstract}
Object. The standard treatment for meningiomas is complete resection, but the proximity of skull base meningiomas to important neurovascular structures makes complete excision of the lesion difficult or impossible. The authors analyzed the mid- and long-term results obtained in patients treated with postresection Gamma Knife surgery (GKS) for residual or recurrent benign meningiomas of the cranial base.

Methods. Thirty-six patients with residual or recurrent benign meningiomas of the skull base following one or more surgical procedures underwent GKS. There were 31 women and five men, ranging in age from 22 to 73 years. The median tumor volume was $4.1 \mathrm{ml}$ (range $0.8-20 \mathrm{ml}$ ) and the median radiation dose to the tumor margin was $16 \mathrm{~Gy}$ (range 15-16 Gy).

Results. Patients were followed for a median of 81 months (range 30-141 months) after GKS. At the end of the follow-up period, overall neurological improvement was observed in 16 patients (44.4\%), whereas the condition in 20 patients $(55.6 \%)$ was unchanged. One patient suffered transient cerebral edema 6 months after GKS. Based on imaging documentation, a partial response was seen in five patients (13.9\%), the disease remained stable in 30 patients $(83.3 \%)$, and in one patient $(2.8 \%)$ there was an increase in tumor size. The actuarial progression-free survival rate was $100 \%$ at 5 years and $94.7 \%$ at 10 years.

Conclusions. Gamma Knife surgery was shown to be an excellent adjunct to resection because of its durable rate of tumor control and low toxicity. It should be initially considered along with surgery for the treatment of complex skull base meningiomas. (DOI: 10.3171/FOC-07/10/E6)
\end{abstract}

\section{KEY WORDS - cranial base tumor - Gamma Knife • long-term follow-up • meningioma - stereotactic radiosurgery $\bullet$ tumor control}

I $\mathrm{N}$ cases of meningioma complete resection of the lesion has historically been the treatment of choice, resulting in a less than $20 \%$ recurrence rate..$^{1,5,20}$ However, despite substantive advances in microsurgery, total removal of skull base meningiomas, particularly those involving the cavernous sinus or clivus, is controversial, as resection can be difficult and fraught with significant morbidity due to cranial nerve damage. ${ }^{4,5,23}$ In cases of cavernous sinus meningiomas, the invasion of cranial nerves, ICA, and pituitary gland can make complete removal impossible. ${ }^{17,29}$ To that end, the authors of several reports have emphasized the use of subtotal resection for improved functional outcome over complete resection of skull base lesions to minimize the risk of permanent postoperative cranial nerve deficits. . $, 5,24,25,27$ Unfortunately, long-term outcome after subtotal resection of cranial base meningiomas is associated with an unacceptably high symptomatic recurrence rate. ${ }^{20}$

Abbreviations used in this paper: $\mathrm{EBRT}=$ external beam radiation therapy; GKS = Gamma Knife surgery; ICA = internal carotid artery.
It is clear that the optimal management of complex skull base meningiomas is not always achievable with surgery alone. As a result, there has been great interest in a combined management strategy involving the application of GKS following resection, or as a stand-alone treatment for small and midsized meningiomas. Several reports have shown GKS results comparable with those obtained in association with Simpson Grade I resections; however, few authors have documented long-term experience with that modality. $2,11,12,16,18,21,31,37$ In this retrospective study of benign cranial base meningiomas, we evaluate the mid- and long-term efficacy of GKS following resection focusing on neurological and imaging outcomes.

\section{Clinical Material and Methods}

\section{Patient Population}

Between September 1994 and November 2004, 211 patients underwent GKS for intracranial meningiomas at University of Southern California University Hospital. Of these, 
36 patients had had prior surgery for a benign meningioma of the cranial base and at least 2 years of follow-up; they form the population for this study. No patient received EBRT or chemotherapy prior to GKS. The median age of the patients was 55 years (range $22-73$ years). There were 31 women and five men. Tumor location was classified as originating in the cavernous sinus, petroclivus, sphenoid wing, and at other skull base sites (Table 1). Follow-up data included information on neurological deficits, miscellaneous symptoms, tumor size, and toxicity. Data were obtained through a review of the patients' charts, the Gamma Knife database, relevant imaging studies, and phone interviews. Prior to the start of this study, institutional review board approval was obtained.

\section{Meningioma Resection}

All patients underwent at least one surgical procedure prior to receiving GKS, including two patients who had combined operations and two who had a second surgery after tumor recurrence. Of the 32 patients in whom a single procedure was performed, 13 underwent a pterional craniotomy, five a temporal craniotomy with an extended middle fossa approach, five a frontal craniotomy, three a transsphenoidal craniotomy, two an orbitozygomatic approach, two a transpetrosal approach, and one each a retrosigmoid and extreme-lateral inferior transtubercular exposure. In the two patients who underwent combined procedures, one was treated with the orbitozygomatic and transpetrosal approaches and the other with the pterional and transpetrosal approaches. Two patients had undergone a second surgery for a recurrent meningioma prior to GKS: one who had a bicoronal craniotomy followed by a pterional approach 9 years later and the other who had two retrosigmoid craniotomies 12 years apart. The Simpson grade for the surgery most proximate to GKS was I in one patient, II in two patients, III in three patients, and IV in the remaining 30. In all cases the pathological diagnosis was consistent with a benign (World Health Organization Grade I) meningioma. The interval between the last operation and GKS ranged from 1 to 139 months (median 6 months). In 18 patients GKS was delayed for at least 6 months, including four of the six patients with a Simpson Grade I to III resection. One patient with a Simpson Grade II and a second with a Grade III resection underwent GKS 3 and 4 months, respectively, after resection for tumor within the cavernous sinus.

\section{Radiosurgical Technique}

All patients were treated with the Leksell Gamma Knife unit model U until May 2000 and with the model C thereafter (Elekta Instruments AB). Short-acting general and local anesthesia were used during placement of the Leksell stereotactic coordinate frame. Conscious sedation was applied for the remainder of the procedure and was monitored by a neuroanesthesiologist. After frame placement, a highresolution contrast-enhanced axial MR image (slice thickness $1-2 \mathrm{~mm}$ with zero gap) was obtained. Image reconstruction of the sagittal and coronal planes was used when near target structures. For all treatment planning a neuroradiologist was present to provide assistance with the identification of the lesion and adjacent critical structures such as the optic apparatus. The radiation dose distribution was carefully shaped to the lesion contour to minimize the dose to the normal adjacent brain and cranial nerves. This treat- ment optimization very frequently required the use of selective beam blocking. The median tumor volume was $4.1 \mathrm{ml}$ (range $0.8-20 \mathrm{ml}$ ) and the median conformity index was 1.62 (range 1.24-2.88). The median radiation dose to the tumor margin was 16 Gy (range 15-16 Gy) and the median maximal dose was 32 Gy (range 21.3-32 Gy). A median of seven isocenters (range 1-12) was required to treat the tumors, most of which were irregularly shaped. All patients were observed for approximately 2 hours after GKS prior to being released to home if their condition was stable. One patient required posttreatment hospitalization. Follow-up imaging was performed at 3, 6, and 12 months and then annually for 5 years. Tumors that were stable in size or exhibited regression were then imaged biannually.

Tumor progression was defined on images per the Response Evaluation Criteria in Solid Tumors. ${ }^{32}$ According to these criteria, a partial response is defined as a decrease in size of at least $30 \%$ and progressive disease is defined as a $20 \%$ or greater increase in the largest dimension.

\section{Statistical Analysis}

The actuarial rate of tumor control was calculated using the Kaplan-Meier method.

\section{Results}

\section{Clinical Outcome}

Thirty-six patients were followed for a median of 81 months (range 30-141 months, mean 78 months) after GKS. Two patients died of intercurrent disease during the follow-up period, one of a myocardial infarction 32 months after GKS and the other of renal cell carcinoma 34 months after GKS.

Clinical improvement was defined as a reduction in a pre-GKS neurological deficit or symptom. During the follow-up period, overall improvement was observed in 16 patients (44.4\%) and there was no change in 20 (55.6\%) (Table 2). The distribution of pre-GKS neurological disorders and their post-GKS change is detailed in Table 3.

\section{Imaging-Documented Outcome}

Serial MR imaging revealed a partial response in five patients (13.9\%), stable disease in $30(83.3 \%)$, and an increased tumor size in one (2.8\%) (Table 2). Applying the Kaplan-Meier method, the progression-free survival rate was $100 \%$ at 5 years and $94.7 \%$ at 10 years (Fig. 1).

Tumor progression was observed in one patient. That patient was a 53-year-old woman who initially underwent a transsphenoidal craniotomy and subtotal resection of a tumor involving the sella and cavernous sinus; 4 months later GKS (a 16-Gy dose at the margin) was performed. The treatment primarily targeted the tumor in the cavernous sinus, but the tail, which extended into the tentorial incisura, was not fully covered. The tumor recurred 75 months later in the tail, at the margin of what had been previously treated. A second GKS targeting the area of recurrence was undertaken, but 3 years later we observed further progression that necessitated another resection and EBRT. This case was otherwise very similar to the rest in this series in terms of the initial GKS treatment parameters. 
TABLE 1

Location of meningioma in 36 patients who underwent postoperative GKS

\begin{tabular}{lc}
\hline \hline \multicolumn{1}{c}{ Tumor Location } & No. of Cases $(\%)$ \\
\hline cavernous sinus & $17(47)$ \\
petroclivus & $9(25)$ \\
sphenoid wing & $4(11)$ \\
other site & $6(17)$ \\
optic canal & 2 \\
olfactory groove & 2 \\
cerebellopontine angle & 1 \\
sella & 1 \\
total & $36(100)$ \\
\hline
\end{tabular}

\section{Treatment-Related Toxicity}

Complications were classified according to whether they presented early or late. One patient who was treated for a tumor involving the cavernous sinus, medial sphenoid wing, and petroclival areas (15 Gy to the margin and had a treatment volume of $6.2 \mathrm{ml}$ ) developed severe headache, nausea, and vomiting after GKS and required an overnight hospital admission for symptom control. There were no other early complications associated with the procedure or anesthesia.

A delayed complication developed in one patient. Six months after GKS (15 Gy to the margin) treatment of a large petroclival meningioma (tumor volume $20 \mathrm{ml}$, treatment volume $25 \mathrm{ml}$ ) the patient presented with headaches and papilledema due to severe temporal lobe edema. Dexamethasone treatment was initiated, resulting in resolution of symptoms 1 week later. No patient developed new cranial nerve deficits after GKS.

\section{Discussion}

The traditional goal of meningioma surgery has been complete resection; however, the complex nature of skull base meningiomas and their intimate proximity to important neurovascular structures makes management difficult. Currently, controversy exists as to whether skull base meningiomas, as well as those involving the cavernous sinus or clivus in particular, are best treated with radical resection or with subtotal resection followed by GKS of the residual lesion. The authors of several reports have advocated aggressive removal of meningiomas involving the cavernous sinus, citing the relatively low morbidity rate achieved with modern microsurgical techniques. ${ }^{5,14}$

Despite the enthusiasm of some authors regarding the safety and feasibility of resecting cavernous sinus meningiomas, surgical goals must be tempered in cases in which local invasion may be present, making a surgical cure difficult or impossible. Sen and Hague ${ }^{29}$ examined six patients with benign meningiomas involving the cavernous sinus and compared data with those obtained in healthy control individuals. They found that meningiomas tended to infiltrate cranial nerves, the ICA, and to a lesser degree the pituitary gland. Interestingly, trigeminal impairment was not correlated with invasion, nor was narrowing of the ICA always present when there was invasion of its adventitia. Larson et al. ${ }^{17}$ also documented two cases of cranial nerve infiltration from a benign menigioma, and Kotapka et al. ${ }^{15}$
TABLE 2

Outcome after GKS

\begin{tabular}{lccl}
\hline \hline \multirow{2}{*}{ Outcome } & \multicolumn{3}{c}{ No. of Patients (\%) } \\
\cline { 2 - 4 } & Improved & Stable & Worse \\
\hline neurological & $16(44.4)$ & $20(55.6)$ & $0(0)$ \\
imaging & $5(13.9)$ & $30(83.3)$ & $1(2.8)$ \\
\hline
\end{tabular}

and Shaffrey et al..$^{30}$ similarly found infiltration of the ICA. Taken together, preoperative planning must account for the fact that in some cases of benign cavernous sinus meningiomas there is neurovascular invasion. Although radical resection of meningiomas involving the cavernous sinus may extend progression-free survival, ${ }^{5}$ surgery short of an en bloc resection with or without ICA grafting or bypass may not produce a cure. ${ }^{30}$

Our study, along with the handful of other reports containing long-term data, supports GKS as a highly effective alternative to aggressive resection. We undertook GKS in patients with an initial subtotal resection or with recurrent disease and found the 5- and 10-year actuarial progressionfree survival rates to be 100 and $94.7 \%$, respectively. Furthermore, because the patient with post-GKS progressive disease had her tumor growth in an area not adequately covered by the treatment plan, we believe that, had this not occurred, our progression-free survival rate might have been $100 \%$. Zachenhofer et al. ${ }^{37}$ reported on 36 patients with cranial base meningiomas, 25 of whom had a history of surgery, with a tumor control rate of $94 \%$ in a mean duration of 103 months. Kreil and colleagues ${ }^{16}$ reviewed data obtained in 200 patients treated with GKS for benign skull base meningiomas, 99 of whom had undergone a prior resection, and found actuarial 5- and 10-year progression-free survival rates of 98.5 and $97.2 \%$. Other authors have also used GKS for skull base meningiomas and reported a tumor control rate exceeding $90 \%$ (Table 4).2,7,12, $18,19,21,26$

In this report we exclusively reviewed data obtained in patients who had undergone a microsurgical resection prior to GKS. Tumor debulking has several advantages, such as immediately treating neurological deficits caused by tumor

TABLE 3

Summary of neurological deficits before and after GKS

\begin{tabular}{|c|c|c|c|}
\hline \multirow[b]{3}{*}{ Deficit } & \multicolumn{3}{|c|}{ No. of Patients } \\
\hline & \multirow[b]{2}{*}{ Pre-GKS } & \multicolumn{2}{|c|}{ Post-GKS } \\
\hline & & Improved & Stable \\
\hline reduced visual acuity & 7 & 2 & 5 \\
\hline $\begin{array}{l}\text { oculomotor palsy } \\
\text { trigeminal }\end{array}$ & 6 & 1 & 5 \\
\hline sensory loss & 8 & 2 & 6 \\
\hline neuralgia & 2 & & 2 \\
\hline both & 1 & 1 & \\
\hline abducens palsy & 12 & 9 & 3 \\
\hline hearing loss & 3 & 1 & 2 \\
\hline hemiplegia & 1 & 1 & \\
\hline behavioral changes & 2 & 2 & \\
\hline dizziness & 2 & 2 & \\
\hline ataxia & 1 & 1 & \\
\hline
\end{tabular}




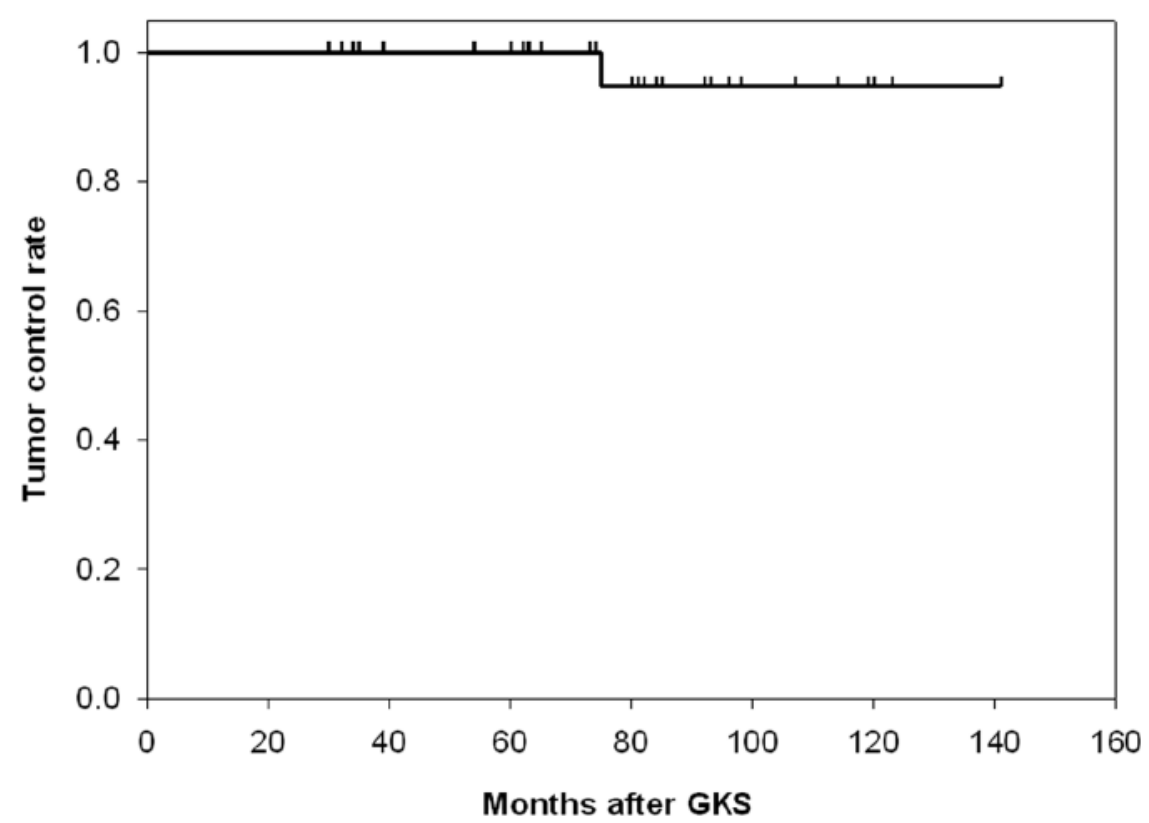

FIG. 1. Graph of a Kaplan-Meier curve showing tumor control rates of $100 \%$ at 5 years and $94.7 \%$ at 10 years in 36 patients treated with postoperative GKS.

compression, enabling a histological diagnosis to be made, and decreasing the size of a large tumor to that treatable by GKS. Although most patients in this study were treated with the paradigm of a subtotal resection followed by GKS, there were some in which a Simpson Grade I to III resection was performed and GKS was delayed until there was a recurrence.

Despite the advantages of surgical debulking, several centers have had excellent results treating small- and midsized meningiomas with initial GKS. As with postresection GKS, patients who underwent GKS alone also had midand long-term tumor control rates exceeding $90 \%$. $^{2,7,12,18,26,37}$ Gamma Knife surgery alone can therefore be considered in patients with meningiomas less than approximately $3 \mathrm{~cm}$ who have significant comorbidities or tumors in locations that are difficult to access.
Compared with microsurgical resection, GKS has a lower rate of postprocedure permanent neurological deficits. ${ }^{5,14}$, 22,23,25,27 That rate has greatly decreased over the last several decades due to a worldwide dose deescalation and improved targeting accuracy. ${ }^{22}$ With current techniques, significant toxicity can be expected in fewer than $5 \%$ of cases. ${ }^{2,12,16}$ In our series no patient had worsening cranial nerve function, but one patient developed cerebral edema. Although uncommon, post-GKS peritumoral edema is a well-recognized entity and appears to preferentially affect nonbasally located meningiomas. ${ }^{8,9,34}$ In our case, the edema may have been a result of the high treatment volume (25 ml).

In this study there were several more patients with clinical improvement than imaging improvement. The reason for that was multifactorial. The primary reason was that

TABLE 4

Summary of selected series in which GKS was used to treat cranial base meningiomas

\begin{tabular}{|c|c|c|c|c|c|c|c|c|}
\hline \multirow[b]{2}{*}{ Series } & \multirow{2}{*}{$\begin{array}{l}\text { No. of } \\
\text { Patients }\end{array}$} & \multicolumn{2}{|c|}{ Follow-Up (mos) } & \multirow{2}{*}{$\begin{array}{c}\text { Margin } \\
\text { Dose (Gy) }\end{array}$} & \multirow{2}{*}{$\begin{array}{l}\text { Tumor } \\
\text { Size }\end{array}$} & \multicolumn{2}{|c|}{ Treatment History (\%) } & \multirow{2}{*}{$\begin{array}{c}\text { Tumor } \\
\text { Control } \\
\text { Rate }(\%)\end{array}$} \\
\hline & & Median & Range & & & Op & EBRT & \\
\hline Duma et al., 1993 & 34 & 24 & $6-54$ & 16 & $5.2 \mathrm{~cm}^{3}$ & 82 & 9 & 100 \\
\hline Subach et al., 1998 & 62 & 37 & $4-95$ & 15 & $13.7 \mathrm{~cm}^{3}$ & 63 & 11 & 86.7 \\
\hline Morita et al., 1999 & 88 & 35 & $12-83$ & 16 & $10 \mathrm{~cm}^{3}$ & 56 & 7 & 95 \\
\hline Aichholzer et al., 2000 & 46 & 48 & $36-76$ & 16 & $23.5 \mathrm{~mm}$ & 67 & 7 & 96 \\
\hline Lee et al., 2002 & 159 & 39 & $2-145$ & 13 & $6.5 \mathrm{~cm}^{3}$ & 48 & 1 & $93.1 / 93.1 *$ \\
\hline Iwai et al., 2003 & 42 & 49 & $18-84$ & 11 & $14.7 \mathrm{~cm}^{3}$ & 52 & 0 & 90.5 \\
\hline Roche et al., 2003 & 32 & 53 & $24-118$ & 13 & $2.3 \mathrm{~cm}^{3}$ & 25 & 0 & 100 \\
\hline Maruyama et al., 2004 & 40 & 47 & $14-79$ & 16 & $6.7 / 4.0 \mathrm{~cm}^{3} \dagger$ & 58 & 0 & 94.1 \\
\hline Kreil et al., 2005 & 200 & 95 & $60-144$ & 12 & $6.5 \mathrm{~cm}^{3}$ & 50 & 0 & $98.5 / 97.2 *$ \\
\hline Zachenhofer et al., 2006 & 36 & 103 & $70-133$ & 17 & $20 \mathrm{~mm}$ & 69 & - & 94 \\
\hline present study & 36 & 81 & $30-141$ & 16 & $4.1 \mathrm{~cm}^{3}$ & 100 & 0 & $100 / 94.7 *$ \\
\hline
\end{tabular}

* Values indicate the 5- and 10-year actuarial progression-free survival rates, respectively.

$\dagger$ Primary/recurrent tumor volume. 
several patients suffered surgery-related neurological compromise. Those neurological deficits spontaneously began to recover during which time patients underwent GKS. A second reason was that some patients with preoperative deficits had continued improvement as a result of surgical decompression rather than GKS. Lastly, in three of the patients who improved clinically, there had been a decrease in tumor size after GKS; however, the disease was classified as stable because the decrease in tumor size was not great enough to categorize the response as partial.

Treatment of dural tails with GKS can significantly increase the volume that is radiated, the length of treatment, and the intricacy of the plan. In our one patient with a recurrent tumor, the recurrence developed in the dural tail at the margin of the initial treatment. The importance of the dural tail has been controversial, with some authors ascribing it

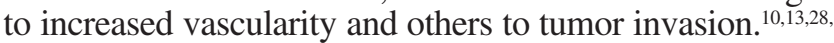
33,35,36 Histological examination has shown that although some cases are due solely to increased vascular permeability, ${ }^{28}$ dilation, ${ }^{33}$ or congestion, ${ }^{13}$ the dural tail can in other cases contain a tumor. ${ }^{10,13,36}$ The role of the dural tail in GKS was studied by DiBiase et al. ${ }^{6}$ who found the 5 -year disease-free survival to be $96.0 \%$ when the dural tail was treated compared with $77.9 \%$ when it was not $(p=0.038)$. We agree with DiBiase et al. that the dural tail should be covered in the treatment plan.

\section{Conclusions}

Residual or recurrent benign meningiomas of the skull base can be treated by GKS with excellent tumor control and a very low morbidity rate. Gamma Knife surgery should be considered as an initial treatment along with microsurgery to maximize tumor control while minimizing treatment-related complications.

\section{Disclosure}

No financial support in any form was received in conjunction with the generation of this submission and none of the authors has any personal or institutional financial interest in drugs, materials, or devices described in this submission.

\section{References}

1. Adegbite AB, Khan MI, Paine KW, Tan LK: The recurrence of intracranial meningiomas after surgical treatment. J Neurosurg 58:51-56, 1983

2. Aichholzer M, Bertalanffy A, Dietrich W, Roessler K, Pfisterer W, Ungersboeck K, et al: Gamma knife radiosurgery of skull base meningiomas. Acta Neurochir (Wien) 142:647-653, 2000

3. Couldwell WT, Fukushima T, Giannotta SL, Weiss MH: Petroclival meningiomas: surgical experience in 109 cases. J Neurosurg 84:20-28, 1996

4. De Jésus O, Sekhar LN, Parikh HK, Wright DC, Wagner DP: Long-term follow-up of patients with meningiomas involving the cavernous sinus: recurrence, progression, and quality of life. Neurosurgery 39:915-920, 1996

5. DeMonte F, Smith HK, al-Mefty O: Outcome of aggressive removal of cavernous sinus meningiomas. J Neurosurg 81:245251, 1994

6. DiBiase SJ, Kwok Y, Yovino S, Arena C, Naqvi S, Temple R, et al: Factors predicting local tumor control after gamma knife stereotactic radiosurgery for benign intracranial meningiomas. Int J Radiat Oncol Biol Phys 60:1515-1519, 2004
7. Duma CM, Lunsford LD, Kondziolka D, Harsh GR IV, Flickinger JC: Stereotactic radiosurgery of cavernous sinus meningiomas as an addition or alternative to microsurgery. Neurosurgery 32: 699-705, 1993

8. El Shehaby A, Ganz JC, Reda WA, Hafez A: Mechanisms of edema after gamma knife surgery for meningiomas. Report of two cases. J Neurosurg 102 (Suppl):1-3, 2005

9. Ganz JC, Schröttner O, Pendl G: Radiation-induced edema after Gamma Knife treatment for meningiomas. Stereotact Funct Neurosurg 66 (1 Suppl):129-133, 1996

10. Goldsher D, Litt AW, Pinto RS, Bannon KR, Kricheff II: Dural "tail" associated with meningiomas on Gd-DTPA-enhanced MR images: characteristics, differential diagnostic value, and possible implications for treatment. Radiology 176:447-450, 1990

11. Hart D, Giannotta S: Complex cranial base meningioma: combined management. Tech Neurosurg 9:86-92, 2003

12. Iwai $Y$, Yamanaka K, Ishiguro T: Gamma knife radiosurgery for the treatment of cavernous sinus meningiomas. Neurosurgery 52:517-524, 2003

13. Kawahara Y, Niiro M, Yokoyama S, Kuratsu J: Dural congestion accompanying meningioma invasion into vessels: the dural tail sign. Neuroradiology 43:462-465, 2001

14. Knosp E, Perneczky A, Koos WT, Fries G, Matula C: Meningiomas of the space of the cavernous sinus. Neurosurgery 38: 434-444, 1996

15. Kotapka MJ, Kalia KK, Martinez AJ, Sekhar LN: Infiltration of the carotid artery by cavernous sinus meningioma. J Neurosurg 81:252-255, 1994

16. Kreil W, Luggin J, Fuchs I, Weigl V, Eustacchio S, Papaefthymiou G: Long term experience of gamma knife radiosurgery for benign skull base meningiomas. J Neurol Neurosurg Psychiatry 76:1425-1430, 2005

17. Larson JJ, van Loveren HR, Balko MG, Tew JM Jr: Evidence of meningioma infiltration into cranial nerves: clinical implications for cavernous sinus meningiomas. J Neurosurg 83:596-599, 1995

18. Lee JY, Niranjan A, McInerney J, Kondziolka D, Flickinger JC, Lunsford LD: Stereotactic radiosurgery providing long-term tumor control of cavernous sinus meningiomas. J Neurosurg 97: 65-72, 2002

19. Maruyama K, Shin M, Kurita H, Kawahara N, Morita A, Kirino T: Proposed treatment strategy for cavernous sinus meningiomas: a prospective study. Neurosurgery 55:1068-1075, 2004

20. Mathiesen T, Lindquist C, Kihlstrom L, Karlsson B: Recurrence of cranial base meningiomas. Neurosurgery 39:2-9, 1996

21. Morita A, Coffey RJ, Foote RL, Schiff D, Gorman D: Risk of injury to cranial nerves after gamma knife radiosurgery for skull base meningiomas: experience in 88 patients. J Neurosurg 90: 42-49, 1999

22. Norén G: Long-term complications following gamma knife radiosurgery of vestibular schwannomas. Stereotact Funct Neurosurg 70 (1 Suppl):65-73, 1998

23. O'Sullivan MG, van Loveren HR, Tew JM Jr: The surgical resectability of meningiomas of the cavernous sinus. Neurosurgery 40:238-247, 1997

24. Ojemann RG: Skull-base surgery: a perspective. J Neurosurg 76:569-570, 1992

25. Ringel F, Cedzich C, Schramm J: Microsurgical technique and results of a series of 63 spheno-orbital meningiomas. Neurosurgery 60 (4 Suppl):214-222, 2007

26. Roche PH, Pellet W, Fuentes S, Thomassin JM, Regis J: Gamma knife radiosurgical management of petroclival meningiomas results and indications. Acta Neurochir (Wien) 145:883-888, 2003

27. Sekhar LN, Swamy NK, Jaiswal V, Rubinstein E, Hirsch WE Jr, Wright DC: Surgical excision of meningiomas involving the clivus: preoperative and intraoperative features as predictors of postoperative functional deterioration. J Neurosurg 81:860-868, 1994

28. Sekiya T, Manabe H, Iwabuchi T, Narita T: [The dura mater adja- 


\section{Davidson et al.}

cent to the attachment of meningiomas: its enhanced MR imaging and histological findings.] No Shinkei Geka 20:1063-1068, 1992

29. Sen C, Hague K: Meningiomas involving the cavernous sinus: histological factors affecting the degree of resection. J Neurosurg 87:535-543, 1997

30. Shaffrey ME, Dolenc VV, Lanzino G, Wolcott WP, Shaffrey CI: Invasion of the internal carotid artery by cavernous sinus meningiomas. Surg Neurol 52:167-171, 1999

31. Subach BR, Lunsford LD, Kondziolka D, Maitz AH, Flickinger JC: Management of petroclival meningiomas by stereotactic radiosurgery. Neurosurgery 42:437-445, 1998

32. Therasse P, Arbuck SG, Eisenhauer EA, Wanders J, Kaplan RS, Rubinstein L, et al: New guidelines to evaluate the response to treatment in solid tumors. European Organization for Research and Treatment of Cancer, National Cancer Institute of the United States, National Cancer Institute of Canada. J Natl Cancer Inst 92:205-216, 2000

33. Tokumaru A, O'uchi T, Eguchi T, Kawamoto S, Kokubo T, Suzuki M, et al: Prominent meningeal enhancement adjacent to meningioma on Gd-DTPA-enhanced MR images: histopathologic correlation. Radiology 175:431-433, 1990
34. Vermeulen S, Young R, Li F, Meier R, Raisis J, Klein S, et al: A comparison of single fraction radiosurgery tumor control and toxicity in the treatment of basal and nonbasal meningiomas. Stereotact Funct Neurosurg 72 (1 Suppl):60-66, 1999

35. Wallace EW: The dural tail sign. Radiology 233:56-57, 2004

36. Wilms G, Lammens M, Marchal G, Van Calenbergh F, Plets C, Van Fraeyenhoven L, et al: Thickening of dura surrounding meningiomas: MR features. J Comput Assist Tomogr 13: 763-768, 1989

37. Zachenhofer I, Wolfsberger S, Aichholzer M, Bertalanffy A, Roessler K, Kitz K, et al: Gamma-knife radiosurgery for cranial base meningiomas: experience of tumor control, clinical course, and morbidity in a follow-up of more than 8 years. Neurosurgery 58:28-36, 2006

Manuscript submitted July 16, 2007.

Accepted August 29, 2007.

Address correspondence to: Laurence Davidson, M.D., Los Angeles County-University of Southern California Medical Center, 1200 North State Street, Suite 5046, Los Angeles, California 90033. email: ldavidso@usc.edu. 